\title{
Prediction of the Service Life of a Reinforced Concrete Column under Chloride Environment
}

\author{
Mohammad K. Alkam ${ }^{1}$ and Maha Alqam² \\ ${ }^{1}$ Mechanical Engineering Department, Jordan University of Science and Technology, Irbid 22110, Jordan
}

${ }^{2}$ Department of Civil Engineering, The University of Jordan, Amman 11942, Jordan

Correspondence should be addressed to Mohammad K. Alkam; alkam@just.edu.jo

Received 11 July 2015; Accepted 8 October 2015

Academic Editor: Pavel Lejcek

Copyright (C) 2015 M. K. Alkam and M. Alqam. This is an open access article distributed under the Creative Commons Attribution License, which permits unrestricted use, distribution, and reproduction in any medium, provided the original work is properly cited.

In the present investigation, service life of a reinforced concrete column exposed to chloride environment has been predicted. This study has been based on numerical simulation of chloride ion diffusion in a concrete column during its anticipated life span. The simulation process has included the concrete cover replacement whenever chloride ion concentration has reached the critical threshold value at the reinforcement surface. Repair scheduling of the concrete column under consideration has been discussed. Effects of the concrete cover thickness and the water cement ratio on the service life of the concrete column at hand have been presented. A new approach for arranging locations of reinforcement steel bars has been introduced. This approach is intended to prolong the service life of the concrete column under consideration against chloride induced corrosion.

\section{Introduction}

Chloride ion penetration into concrete structures is a major cause of reinforcement steel corrosion. Corrosion of reinforcement steel shortens service lives of concrete structures for it causes concrete cracking, reduction of reinforcement cross sectional area, reduction in material strength, reduction in steel ductility, and loss of bond between reinforcement and concrete. Appropriate and periodic maintenance of reinforced concrete structures helps prolong their service lives and improves their durability. Onset of chloride-induced corrosion has been believed to take place when the value of chloride ion concentration at the reinforcement surface exceeds a certain value known as the critical threshold level, CTL. Replacement of the concrete cover before the onset of corrosion takes place protects the concrete structure, extends its service life, and hence improves its safety. Ann and Song [1] have discussed the state of art on the CTL for steel corrosion in concrete in regard to its measurement, representation, and influencing factors. In their study, Ann and Song [1] studied several methods used to raise CTL values, including the use of corrosion inhibitors, coating of steel, and electrochemical treatment.
Theoretical simulation of chloride ion penetration into concrete structures is a powerful tool for setting up proper maintenance schedule of structures. This task has captured the attention of several researchers. Many of these researchers have presented analytical solutions for the problem of chloride ion diffusion into concrete structures. Among these researchers are Crank [2], Cady and Weyers [3], and ThoftChristensen and Hansen [4]. All these solutions have been based on the one-dimensional conservation of species equation, coupled with Fick's law of diffusion, with constant diffusion coefficient. The source of chloride ion has been represented by a prescribed surface ion concentration at the boundary of the concrete structure under investigation. The boundary chloride ion concentration was considered either constant [3,4] or time dependent [2]. Based on the analytical solution presented by Crank [2], Kassir and Ghosn [5] have discussed the onset of corrosion of reinforced concrete bridge decks. In their investigation, Kassir and Ghosn [5] have used a prescribed, time dependent boundary ion concentration which was empirically introduced by Weyers et al. [6].

The service life and maintenance of a concrete structure exposed to chloride ion environment have been investigated by Song et al. [7]. Their investigation was based on numerical 


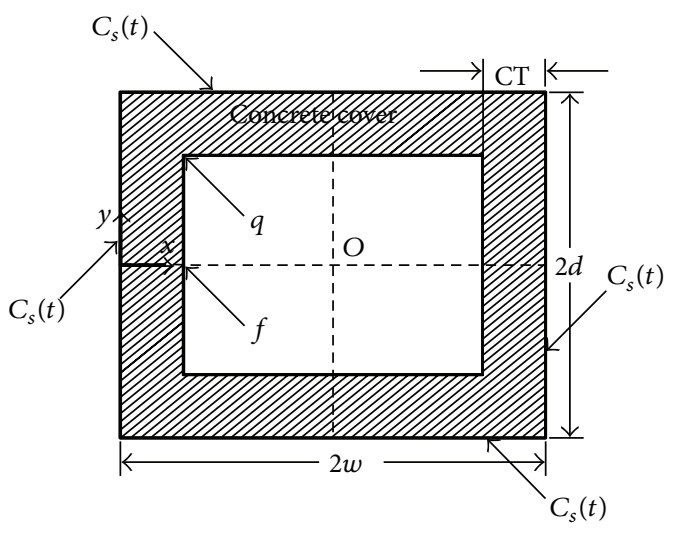

FIGURE 1: Schematic diagram of a cross section of the column under consideration.

solution of the one-dimensional diffusion problem with time dependent diffusion coefficient, as well as time dependent boundary ion concentration. The authors presented chloride ion profiles within a concrete structure before and after multiple replacements of its concrete cover.

In a recent study, Alqam [8] has introduced a transient, two-dimensional simulation of chloride ion diffusion in a concrete column. The authors considered a concrete column with a rectangular cross section exposed to a prescribed, time dependent surface ion concentration. The surface ion concentration was applied to the four boundaries of the cross section of the column. In the study, Alqam [8] has concluded that regions closest to the corners of the column cross section are more susceptible to chloride ion penetration than regions far from the corners. Based on this conclusion, one should set the repair schedule of a reinforced concrete column based on times required for onset of corrosion to take place at steel bars located nearest to the column corners. One-dimensional modeling of chloride ion diffusion into concrete structures is incapable of capturing diffusion activities near the corners of a concrete column.

In the present work, it is intended to discuss service lives and repair of reinforced concrete columns under chloride ion exposure from all column boundaries. This will be accomplished by conducting a transient, two-dimensional simulation of the conjugated chloride diffusion into a concrete column and its concrete cover.

\section{Present Model}

A schematic diagram of the cross section of the concrete column under consideration is shown in Figure 1. The figure shows a column with a width of $2 w$ and a depth of $2 d$. The present mathematical model considers the unsteady, twodimensional diffusion of chloride ion into the concrete cover and the concrete column under consideration. A prescribed time dependent chloride ion concentration, $C_{s}(t)$, is applied to the four outer surfaces of the present column as shown in Figure 1. The four outer surfaces of the present column are located at $x=0$, the left surface, $x=2 w$, the right surface, $y=d$, and the upper surface, and $y=-d$, the lower surface.
As shown in Figure 1, the concrete cover has a thickness of $\mathrm{CT}$ and it is designated by the hatched area.

In the present work, prediction of the service life and repair schedule of a reinforced concrete column has been based on computation of chloride ion concentration at the inner surface of the concrete cover. Due to the twodimensional character of the present diffusion problem, values of chloride ion concentration at the inner surface of the concrete cover are space dependent. Based on the study by Alqam [8], the value of chloride ion concentration reaches the CTL value at the inner corners, such as point $q$, of the concrete cover long before it reaches the CTL value at other locations at the reinforcement surface, such as point $f$. Consequently, the time for concrete cover replacement has been defined, here, as the time elapsed before chloride ion concentration has reached the CTL value at the inner corners of the concrete cover. Transient simulation of chloride ion concentration continues after each repair by considering a fresh concrete cover that is free of chloride ion at the time of repair. The diffusion coefficient of chloride ion into concrete, $D$, has been considered time dependent due to the effect of concrete aging. Right after each repair, the value of the diffusion coefficient of chloride ion into the concrete cover, $D_{c}$, will have a different value than that for the column concrete because each will have a different age.

The present computations have been carried out based on finite difference solution of the conservation of species equation, coupled with Fick's law of diffusion with time and dependent diffusion coefficient. The current governing equations, cast in Cartesian coordinates, take the following form. follows:

Chloride ion diffusion in the concrete column is as

$$
\frac{\partial C}{\partial t}=\frac{\partial}{\partial x}\left(D \frac{\partial C}{\partial x}\right)+\frac{\partial}{\partial y}\left(D \frac{\partial C}{\partial y}\right)
$$

Chloride ion diffusion in the concrete cover is as follows:

$$
\frac{\partial C_{c}}{\partial t}=\frac{\partial}{\partial x}\left(D_{c} \frac{\partial C_{c}}{\partial x}\right)+\frac{\partial}{\partial y}\left(D_{c} \frac{\partial C_{c}}{\partial y}\right) .
$$

The value of the diffusion coefficient of chloride ion into concrete is influenced by the aging process of concrete. Song et al. [9] have reported that the process of cement hydration over time results in connection and condensation of concrete pore structures and consequently affects the value of the diffusion coefficient. In the present model, the diffusion coefficient is considered a decaying function of time according to the following equations [9]:

$$
\begin{aligned}
& D=D_{R}\left(\frac{t_{R}}{t}\right)^{m}, \quad \text { for } t \leq 30 \text { years } \\
& D=D_{R}\left(\frac{t_{R}}{t_{\mathrm{lim}}}\right)^{m}, \text { for } t>30 \text { years, }
\end{aligned}
$$

where $t_{\lim }=30$ years, $D_{R}$ is the diffusion coefficient at a reference time, and $t_{R}=28$ days. The value of $m$ is considered 
0.2 which represents zero content of fly ash and slag [7]. The value of $D_{R}$ is represented as a function of the water cement ratio, $w / c$, as

$$
D_{R}=10^{(-12.06+2.4 w / c)}
$$

After each repair, a fresh concrete cover replaces the old one. The computational time for the new concrete cover is reset to zero for calculating the value of $D_{c}$ using (3)-(4), while the value of $D$ for the original concrete column is calculated based on the original time scale.

The value of the surface chloride concentration, $C_{s}(t)$, depends on many factors, including the ambience of the structure and the distance between the structure and the sea [10]. Several closed form expressions for $C_{s}(t)$ that were developed by previous investigators have been reported by Song et al. [7]. In the present work, the time dependent surface chloride ion concentration, $C_{s}(t)$, based on the closed form solution developed by Song et al. [9] has been be considered, where $C_{s}(t)$ takes the following form:

$$
C_{s}(t)=\alpha \ln (\beta t+1),
$$

where $\beta=3.77$ year $^{-1}$. The value of $\alpha$ is given according to the distance between the structure and the sea, such that $\alpha$ is $1.52,0.76$, and 0.51 , for distances between the structure and the sea of $0,100 \mathrm{~m}$, and $250 \mathrm{~m}$, respectively.

Since similar boundary conditions are applied to the four boundaries of the solution domain, the anticipated chloride ion concentration profiles will have mirror image symmetry around both the horizontal and the transverse axes that pass through the center of the cross section, point $O$, shown in Figure 1. Due to this symmetry, the solution domain of the present governing equations has been limited to the upper left quarter of the column cross section with $0 \leq x \leq$ $w$, and $0 \leq y \leq d$. The present boundary conditions resemble the application of a prescribed surface chloride ion concentration, $C_{s}(t)$, at the left boundary, $x=0$, and the upper boundary, $y=d$. Solution symmetry around the transverse axis that passes through the point $O$ is represented by assigning $\partial C / \partial x$ to zero for $x=w$, while $\partial C / \partial y$ has been set to zero for $y=0$ in order to represent the solution symmetry around the horizontal axis that passes through the point $O$. For an initial chloride ion concentration of zero, the set of initial and boundary conditions are summarized as follows.

Initial Chloride Ion Concentration. At $t=0$, and $0 \leq x \leq w$, and $0 \leq y \leq d$

$$
\begin{aligned}
C(x, y, 0) & =0, \\
C_{c}(x, y, 0) & =0 .
\end{aligned}
$$

Prescribed Chloride Ion Concentration at the Left Surface. At $x=0$, and $0 \leq y \leq d$, and $t \geq 0$

$$
C_{c}(0, y, t)=C_{s}(t) \text {. }
$$

Prescribed Chloride Ion Concentration at the Upper Surface. At $y=d$, and $0 \leq x \leq w$, and $t \geq 0$

$$
C_{c}(x, d, t)=C_{s}(t) .
$$

Symmetry of Chloride Ion Concentration around the Transverse Center Axis. At $x=w$, and $0 \leq y \leq d-\mathrm{CT}$, and $t \geq 0$

$$
\frac{\partial C}{\partial x}=0
$$

$$
\text { At } \begin{gathered}
x=w \text {, and } d-\mathrm{CT} \leq y \leq d, \text { and } t \geq 0 \\
\frac{\partial C_{c}}{\partial x}=0 .
\end{gathered}
$$

Symmetry of Chloride Ion Concentration around the Horizontal Center Axis. At $y=0$, and CT $\leq x \leq w$, and $t \geq 0$

$$
\frac{\partial C}{\partial y}=0 .
$$

$$
\begin{gathered}
\text { At } y=0, \text { and } 0 \leq x \leq \mathrm{CT} \text {, and } t \geq 0 \\
\frac{\partial C_{c}}{\partial y}=0 .
\end{gathered}
$$

Continuity of Chloride Mass Flux at the Upper Interface. At $y=d-\mathrm{CT}$, and $\mathrm{CT} \leq x \leq w$, and $t \geq 0$

$$
D \frac{\partial C}{\partial y}=D_{c} \frac{\partial C_{c}}{\partial y} .
$$

Continuity of Chloride Mass Flux at the Left Interface. At $x=$ $\mathrm{CT}$, and $0 \leq y \leq d-\mathrm{CT}$, and $t \geq 0$

$$
D \frac{\partial C}{\partial x}=D_{c} \frac{\partial C_{c}}{\partial x}
$$

Continuity of Chloride Ion Concentration at the Upper Interface. At $y=d-\mathrm{CT}$, and CT $\leq x \leq w$, and $t \geq 0$

$$
C(x, d-\mathrm{CT}, t)=C_{c}(x, d-\mathrm{CT}, t) .
$$

Continuity of Chloride Ion Concentration at the Left Interface. At $x=\mathrm{CT}$, and $0 \leq y \leq d-\mathrm{CT}$, and $t \geq 0$

$$
C(\mathrm{CT}, y, t)=C_{c}(\mathrm{CT}, y, t) .
$$

\section{Computations}

The present governing equations have been solved using a standard explicit finite difference technique. Central differencing has been applied to all spatial derivatives, while temporal derivatives have been discretized using forward differencing. A uniform spatial grid has been applied to the present solution domain where $\Delta x$ and $\Delta y$ are the grid step sizes in the horizontal, $x$, and the transverse, $y$, directions, respectively. The transient solution of the present governing equations has been carried out using typical time marching with a uniform time step of $\Delta t$. 


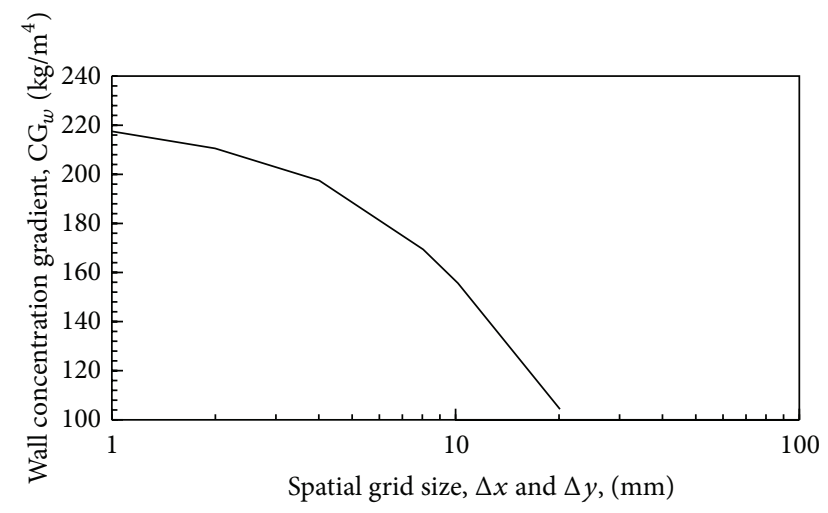

Figure 2: Effect of the spatial grid step size, $\Delta x$ and $\Delta y$, on the gradient of the chloride concentration at the left boundary, $x=0$, for $y=0, t=1$ year, and a time step $\Delta t=8000 \mathrm{~s}$.

The current computations have been performed for a base case with model input parameters that represent a typical reinforced concrete column exposed to a severe chloride environment. Unless stated otherwise, figures exhibited in the present investigation have been constructed using the model input parameters of the base case. These parameters include $w=0.4 \mathrm{~m}, d=0.2 \mathrm{~m}, \mathrm{CT}=75 \mathrm{~mm}, w / c=0.3$, and zero distance between the considered structure and the sea.

A grid sensitivity analysis has been performed in order to select appropriate values of $\Delta x, \Delta y$, and $\Delta t$ for all the computations throughout the current investigation. The sensitivity of the value of chloride ion concentration gradient, $\mathrm{CG}_{w}$, to the spatial grid step size, $\Delta x$ and $\Delta y$, has been shown in Figure 2 for $\Delta t=8000 \mathrm{~s}$. The value of $\mathrm{CG}_{w}$ has been calculated at the center point of the left boundary, $x=0$ and $y=0$, and at $t=1$ year. Using this figure, the present spatial grid has been set up with $\Delta x=\Delta y=1 \mathrm{~mm}$. Having chosen values of $\Delta x$ and $\Delta y$, the sensitivity of $\mathrm{CG}_{w}$ to $\Delta t$ has been examined in Figure 3. Based on Figure 3, $\Delta t$ has been given the value of $1000 \mathrm{~s}$ throughout the entire present computations.

\section{Discussion of Results}

In order to examine the present code, a comparison between the present code computations and those introduced by Song et al. [7] has been constructed and exhibited in Figure 4. The figure shows chloride ion concentration history at the interface between the concrete cover and the concrete column over a time span from $t=0$ until the time of the second repair. The repair is carried out by replacing the old concrete cover by a fresh one that is free from chloride ion. The first repair has been carried out when chloride ion concentration reaches the CTL value at the interface between the concrete cover and the column. The value of CTL was taken as $1.2 \mathrm{~kg} / \mathrm{m}^{3}$ as has been recommended by [1]. This value has been adopted in the present investigation.

It is worth mentioning that Song et al. [7] have considered a one-dimensional analysis that represents an infinitely wide column that is insensitive to the end effects. In order to reproduce the one-dimensional case studied by Song et al. [7],

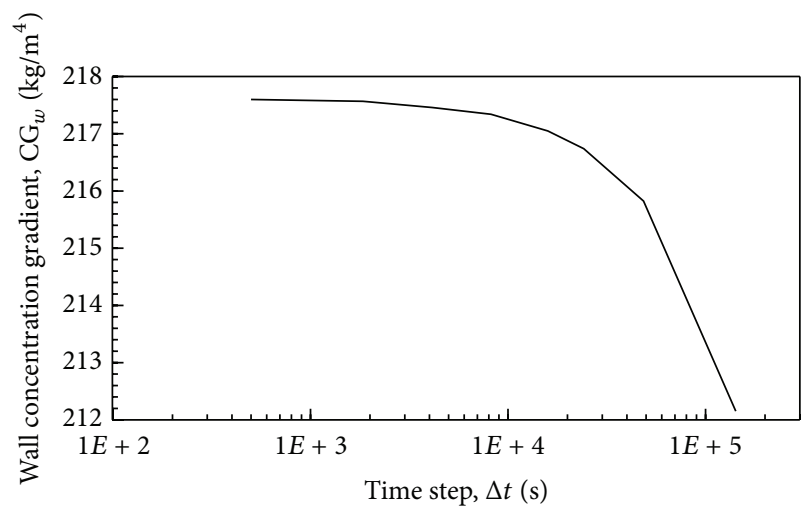

Figure 3: Effect of the time step size, $\Delta t$, on the gradient of the chloride concentration at the left boundary, $x=0$, for $y=0 \mathrm{~m}$, $t=1$ year, and $\Delta x=\Delta y=1 \mathrm{~mm}$.

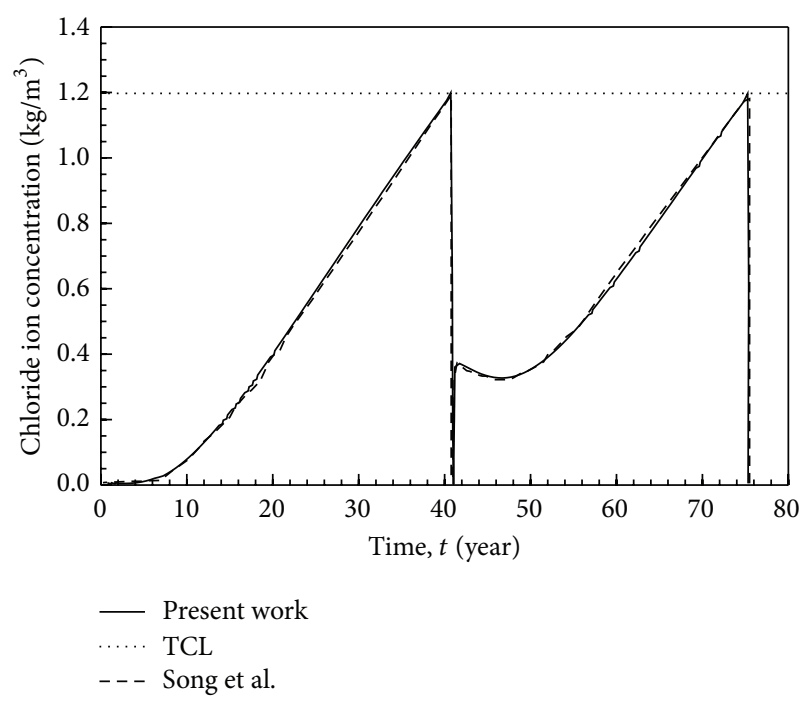

FIgURE 4: History of chloride ion concentration at the interface between the concrete cover and the column. Comparison with computations of Song et al. [7] for a one-dimensional case with $\mathrm{CT}=80 \mathrm{~mm}$.

a zero chloride concentration gradient has been imposed on both the upper and the lower boundaries of the present solution domain, which are represented below.

$$
\begin{gathered}
\text { At } y=0 \text {, and CT } \leq x \leq w \text {, and } t \geq 0 \\
\qquad \frac{\partial C}{\partial y}=0 . \\
\text { At } y=0 \text {, and } 0 \leq x \leq \mathrm{CT} \text {, and } t \geq 0 \\
\frac{\partial C_{c}}{\partial y}=0 .
\end{gathered}
$$

At $y=d$, and $0 \leq x \leq w$, and $t \geq 0$

$$
\frac{\partial C_{c}}{\partial y}=0 .
$$




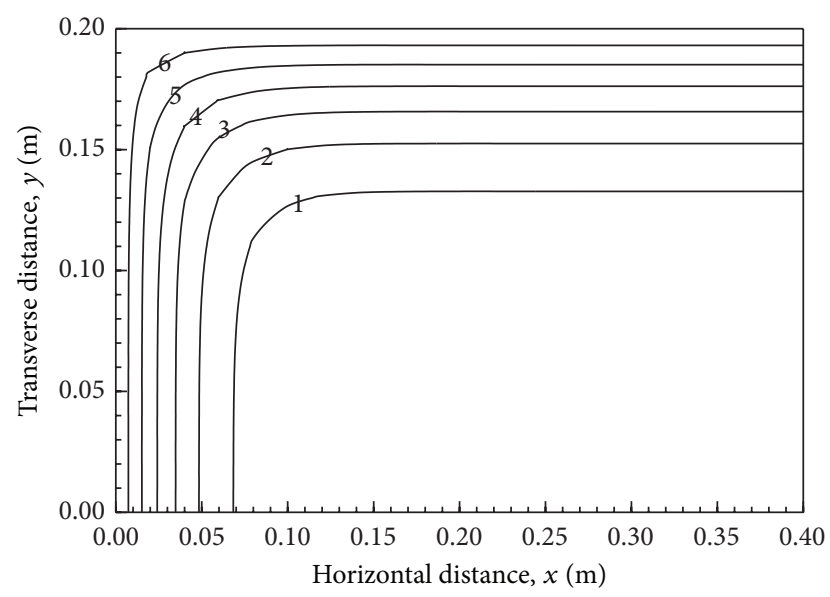

FIgURE 5: Chloride ion isoconcentration contours at $t=25$ years. The figure shows six contours corresponding to chloride ion concentrations of $1,2,3,4,5$, and $6 \mathrm{~kg} / \mathrm{m}^{3}$.

Imposing the boundary conditions represented by (17)-(19) forces chloride to penetrate in the horizontal, $x$, direction only and this redeems the present problem one-dimensional. The comparison held in Figure 4 has been performed for a column with CT $=80 \mathrm{~mm}, w / c$ of 0.3 , and a zero distance from the sea.

Isoconcentration contours of chloride ion at $t=25$ years have been plotted in Figure 5. The figure shows six contours corresponding to chloride ion concentrations of $1,2,3,4,5$, and $6 \mathrm{~kg} / \mathrm{m}^{3}$. The figure shows that chloride penetration is more severe near the corner area because of its proximity to both external surfaces of the concrete cover. In other words, a reinforcement steel bar located at the corner of the column, point $q$ shown in Figure 1, is anticipated to experience corrosion long before a bar located at the middle of the column surface, point $f$ shown in Figure 1. Repair schedule is planned based on the time required for chloride ion concentration to reach the CTL value at the inner surface of the concrete cover. Now, one should be careful upon planning repair schedule of reinforced concrete columns. For example, if the arrangement of reinforcement steel bars includes a corner bar, at point $q$, and a middle bar, at point $f$, the repair should take place when chloride ion concentration reaches the CTL value at point $q$ and not $f$. Otherwise, the repair time would be significantly overestimated. This idea is further clarified by inspecting Figure 6 . This figure shows history of chloride ion concentration over 100 years with two different repair scenarios. In the first scenario, concrete cover is replaced when the corner bar location, at point $q$, reaches the CTL value, while in the second scenario, repair is based on the middle bar location, point $f$. Results shown in Figure 6 show that the first four repairs based on the corner bar take place at around $t=26,51,75$, and 99 years, while the first two repairs based on the middle bar take place at around $t=41$ and 75 years. Quantitatively speaking, if the first repair is based on the middle bar, it will take place 15 years after the corner column has started to suffer a chloride concentration above the CTL value.

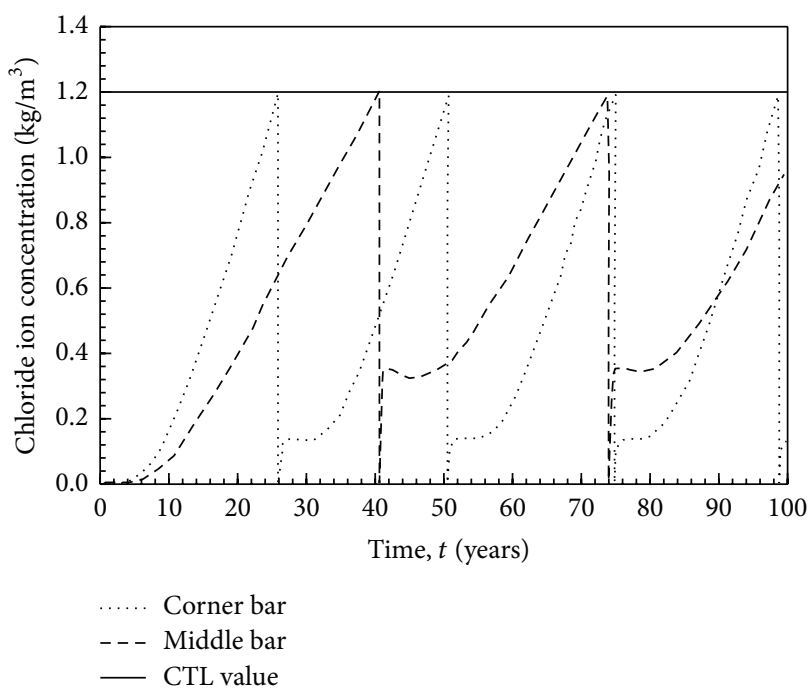

FIGURE 6: History of chloride ion concentration during the first 100 years of the column's life. Comparison between repairs based on the middle steel bar and the corner steel bar.

Effect of the concrete cover thickness, CT, on the repair schedule is shown in Figure 7. The figure shows repair schedule spanned over 100 years for columns with concrete cover thicknesses over a range between $20 \mathrm{~mm}$ and $100 \mathrm{~mm}$. Results shown in Figure 7 give quantitative description of the role of the concrete cover in protecting reinforcement steel bars against chloride-induced corrosion. In the limiting case with $\mathrm{CT}=20 \mathrm{~mm}$, one would need to perform 12 repairs within the first 25 years, while, in the other limiting case with $\mathrm{CT}=100 \mathrm{~mm}$, repairs are suggested at around 41 and 80 years only.

According to (3), the water cement ratio, $w / c$, significantly affects the value of the diffusion coefficient, which in turn affects chloride ion penetration into concrete structures. Due to their exposure to severe chloride surroundings, structures built in marine environment are usually recommended to have relatively lower water cement ratios in order to reduce concrete porosity and, hence, reduce the diffusion coefficient [11]. Effect of water cement ratio on the repair schedule of a reinforced concrete column is shown in Figure 8. It is quite evident that water cement ratio significantly affects repair schedule of a concrete column due to its remarkable influence on chloride diffusion coefficient into concrete. Figure 8 shows that, for a $w / c$ of 0.3 , only four repairs are required within 100 years of the present column life, namely, at $t=26.1,50.6$, 74.8 , and 98.8 years, while, for $w / c$ of 0.5 , one would need 11 repairs within 91 years of the life of the concrete column under consideration.

The time elapsed between two consecutive repairs decreases slightly with time. This is caused by the backward migration of accumulated chloride ion from the concrete column into the fresh concrete cover at early times after each new repair. This can be observed in Figures 4, 6, 7, and 8 .

As has been shown earlier in Figure 6, there were two approaches for column repair scheduling. In the first approach, repair is based on the corner steel bar, while in 


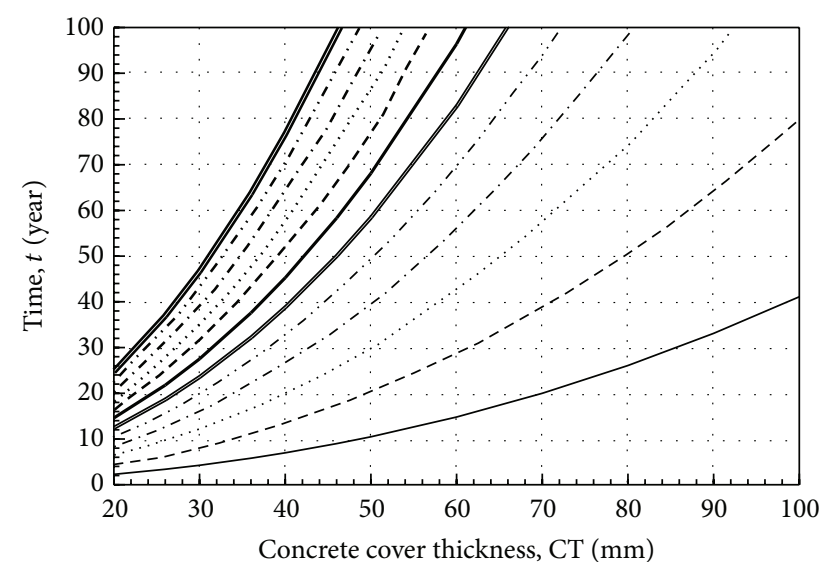

$\begin{array}{ll}- & 1 \text { st repair } \\ \ldots-- & 2 \text { nd repair } \\ \ldots \ldots & 3 \text { rd repair } \\ \ldots-- & 4 \text { th repair }\end{array}$

$-\cdots-5$ th repair
$=$ 6th repair
- 7th repair
---8 th repair

.... 9th repair

...- 10th repair

-..- 11th repair

$=12$ th repair

FIGURE 7: Effect of the concrete cover thickness on the repair schedule of the present concrete column.

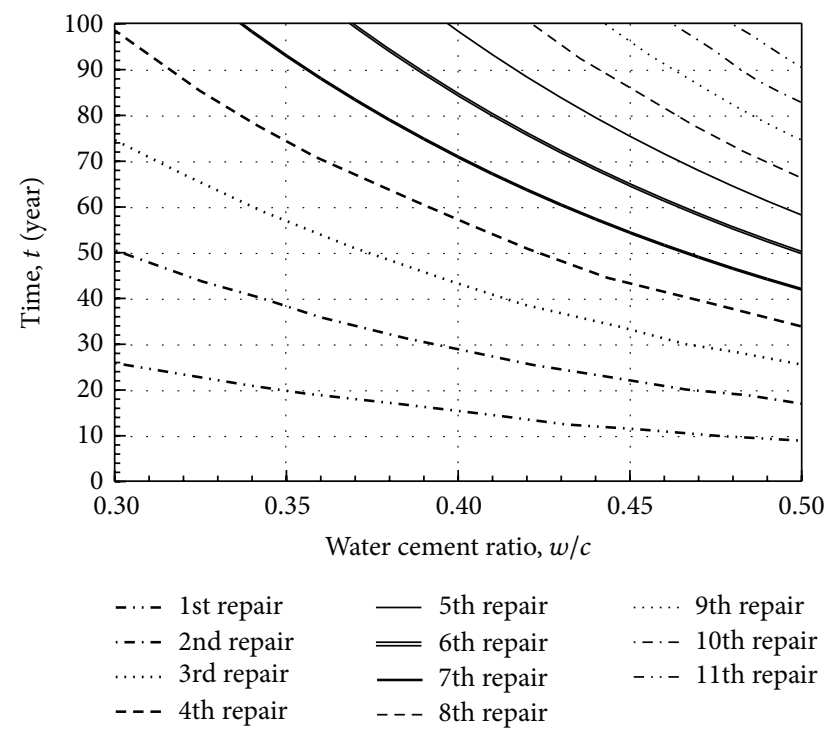

FIGURE 8: Effect of the water cement ratio on the repair schedule of the present concrete column.

the second approach repair is based on the middle steel bar. The previous discussion showed that the later approach resulted in overestimating the time required for proper repair, and consequently, the first approach has been adopted in the present investigation, and yet, it has been recommended for preexisting concrete columns. On the other hand, at the time of repair in the first approach, the value of chloride ion concentration at the location of the middle steel bar, point $f$ in Figure 1, is still significantly below the CTL value. The repair process would be more efficient and less costly if chloride ion concentration reaches the CTL value at all steel bar locations at the time of repair. This could be achieved in newly constructed concrete columns if reinforcement steel

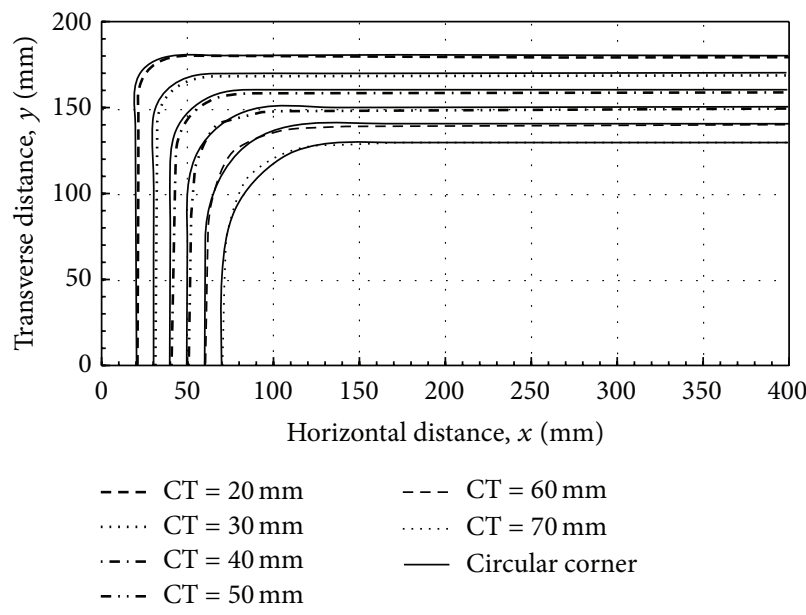

FIGURE 9: Isoconcentration contours with a value of the CTL for various values of concrete cover thicknesses. Circular fillets of the inner concrete cover corners, each with a radius equal to the value of CT, are overlaid. Rectangular, $800 \mathrm{~mm}$ by $400 \mathrm{~mm}$, column.

bars are placed within a contour line that coincides with the isoconcentration contour line. In that case, all steel bar locations will acquire chloride ion concentrations equal to the CTL value at the same time at which repair is scheduled. This proposed approach requires previous knowledge of the isoconcentration contour with a value of the CTL at the desired time of repair before the design of reinforcement is prepared. In that case, the concrete cover thickness, CT, is not constant all around the column because the inner surface of the concrete cover will follow the CTL isoconcentration contour. In order to further explain this idea, the concrete cover thickness, CT, is redefined as the normal distance between the outer surface of the concrete cover and the location of the middle steel bar, point $f$ in Figure 1. Figure 9 has been plotted to show loci of the isoconcentration contours corresponding to the CTL value for different values of the redefined concrete cover thickness, CT. In Figure 9, each contour line provides a guide line for arranging steel bars corresponding to the concrete cover thickness. An approximate rule of thumb has been proposed, for that matter, that helps arrange reinforcement steel bars without having to numerically compute the CTL contours. It has been observed that a CTL contour approximately coincides with a circular fillet at the corners of the concrete column with a radius equal to the value of the concrete cover thickness, CT. Circular fillets at the column corners are plotted in Figure 9 for several values of CT overlaid on the CTL contours computed in the present model. The proposed approach has been examined for a concrete column with a square cross section, $50 \mathrm{~mm}$ by $50 \mathrm{~mm}$, as shown in Figure 10.

\section{Conclusions}

In this work, the service life of a reinforced concrete column exposed to severe chloride environment has been predicted. The present study discussed the repair schedule of the concrete column under consideration. Repair has been based 


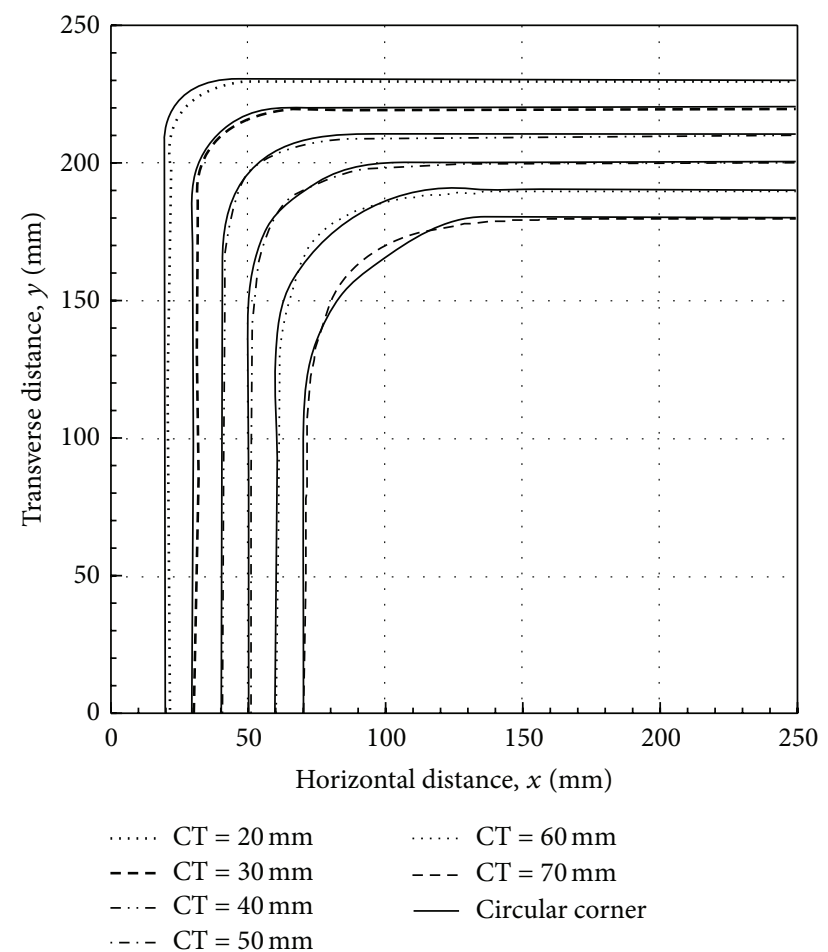

FIGURE 10: Isoconcentration contours with a value of the CTL for various values of concrete cover thicknesses. Circular fillets of the inner concrete cover corners, each with a radius equal to the value of CT, are overlaid. Square, $500 \mathrm{~mm}$ by $500 \mathrm{~mm}$, column.

on the replacement of the concrete cover whenever chloride ion concentration at the reinforcement surface has reached the critical threshold value. Major findings and conclusions are summarized below:

(1) Due to the two-dimensional character of chloride ion diffusion into concrete columns, one-dimensional analysis is incapable of capturing diffusion activities near the corners of the concrete column. The proximity of the near-corner zone to the two external surfaces of the column makes it more susceptible to chloride attacks than other zones far from the corner of the concrete column.

(2) For preexisting concrete columns, concrete cover replacement should take place whenever chloride ion concentration reaches the critical threshold value at the location of the steel bar nearest to the corner of the inner surface of the concrete cover.

(3) The service life of the concrete column under consideration has been found very sensitive to the value of the concrete cover thickness. For a concrete cover thickness of $20 \mathrm{~mm}, 12$ repairs are needed within the first 25 years of the column's life, while, for a concrete cover thickness of $100 \mathrm{~mm}$, only two repairs are required for the first 91 years of the column's life.

(4) The water cement ratio affects significantly the service life of the present concrete column. For a water cement ratio of 0.3 , only four repairs are required within 100 years of the column's life, while, for a water cement ratio of $0.5,11$ repairs are required within the first 91 years of the column's life.

(5) The time elapsed between two consecutive repairs decreases slightly with time.

(6) The service life of the concrete column under consideration can be prolonged if the reinforcement steel bars are located along an isoconcentration contour line. In this case, chloride ion concentration reaches the critical threshold value at locations of all steel bars at the same time, which is the time of repair.

(7) A new approximate rule of thumb has been introduced to define the isoconcentration contour line mentioned in point (5). The rule suggests that the isoconcentration contour line approximately coincides with a circular fillet at the inner corner of the concrete cover with a radius equal to the concrete cover thickness.

\section{Notation}

CT: Concrete cover thickness (m)

C: $\quad$ Chloride ion concentration in the concrete column $\left(\mathrm{kg} / \mathrm{m}^{3}\right)$

$C_{c}: \quad$ Chloride ion concentration in the concrete cover $\left(\mathrm{kg} / \mathrm{m}^{3}\right)$

CTL: Critical threshold level of chloride ion concentration $\left(\mathrm{kg} / \mathrm{m}^{3}\right)$

$\mathrm{CG}_{w}$ : Chloride concentration gradient, $\partial C_{c} / \partial x$, at $x=0$ and $y=0\left(\mathrm{~kg} / \mathrm{m}^{4}\right)$

$C_{s}: \quad$ Surface chloride ion concentration $\left(\mathrm{kg} / \mathrm{m}^{3}\right)$

$d: \quad$ Half of the column depth (m)

D: Diffusion coefficient of chloride ion into the concrete column $\left(\mathrm{m}^{2} / \mathrm{s}\right)$

$D_{c}$ : Diffusion coefficient of chloride ion into the concrete cover $\left(\mathrm{m}^{2} / \mathrm{s}\right)$

$D_{R}$ : Diffusion coefficient at reference time

$$
\left(\mathrm{m}^{2} / \mathrm{s}\right)
$$

$t: \quad$ Time (s)

$t_{R}: \quad$ Reference time (s)

$w$ : Half of the column width (m)

$w / c$ : Water cement ratio

$x$ : $\quad$ Horizontal distance $(\mathrm{m})$

$y: \quad$ Transverse distance $(\mathrm{m})$

Greek Letters

$\alpha: \quad$ Coefficient for $(4)\left(\mathrm{kg} / \mathrm{m}^{3}\right)$

$\beta$ : Coefficient for (4) $\left(\right.$ year $\left.^{-1}\right)$

$\Delta t$ : Value of time step (s)

$\Delta x$ : Spatial grid step size in the $x$ direction $(\mathrm{m})$

$\Delta y$ : Spatial grid step size in the $y$ direction $(\mathrm{m})$

\section{Conflict of Interests}

The authors declare that there is no conflict of interests regarding the publication of this paper. 


\section{References}

[1] K. Y. Ann and H.-W. Song, "Chloride threshold level for corrosion of steel in concrete," Corrosion Science, vol. 49, no. 11, pp. 4113-4133, 2007.

[2] J. Crank, The Mathematics of Diffusion, Oxford Science Publications, Clarendon Press, Oxford, UK, 1975.

[3] P. D. Cady and R. E. Weyers, "Chloride penetration and the deterioration of concrete bridge decks," Cement, Concrete and Aggregates, vol. 5, no. 2, pp. 81-87, 1983.

[4] P. Thoft-Christensen and I. H. Hansen, "Optimal strategy for maintenance of concrete bridges using expert systems," in Structural Safety and Reliability, G. I. Schueller, H. Shinozouka, and J. T. P. Yao, Eds., pp. 939-946, Balheme, Rotterdam, The Netherlands, 1994.

[5] M. K. Kassir and M. Ghosn, "Chloride-induced corrosion of reinforced concrete bridge decks," Cement and Concrete Research, vol. 32, no. 1, pp. 139-143, 2002.

[6] R. E. Weyers, M. G. Fitch, E. P. Larsen, I. Al-Qadi, W. P. Chamberlin, and P. C. Hoffman, Concrete Bridge Protection and Rehabilitation: Chemical and Physical Techniques, Service Life Estimates, (SHRP-S-668), Strategic Highway Research Program, National Research Council, Washington, DC, USA, 1994.

[7] H.-W. Song, H.-B. Shim, A. Petcherdchoo, and S.-K. Park, "Service life prediction of repaired concrete structures under chloride environment using finite difference method," Cement and Concrete Composites, vol. 31, no. 2, pp. 120-127, 2009.

[8] M. Alqam, "Transient chloride ion diffusion in a homogeneous concrete column," The Arabian Journal for Science and Engineering, vol. 39, no. 5, pp. 3633-3640, 2014.

[9] H.-W. Song, S.-W. Pack, and J.-S. Moon, "Durability evaluation of concrete structures exposed to marine environment focusing on a chloride build-up on concrete surface," in Proceedings of the International Workshop on Life Cycle Management of Coastal Concrete Structures, Nagaoka, Japan, 2006.

[10] A. Moriwake, Study on durability and maintenance of reinforced concrete jetty deck against chloride induced deterioration [Ph.D. thesis], Tokyo Institute of Technology, Tokyo, Japan, 1996.

[11] A. Costa and J. Appleton, "Chloride penetration into concrete in marine environment. Part II. Prediction of long term chloride penetration," Materials and Structures, vol. 32, no. 219, pp. 354359, 1999. 

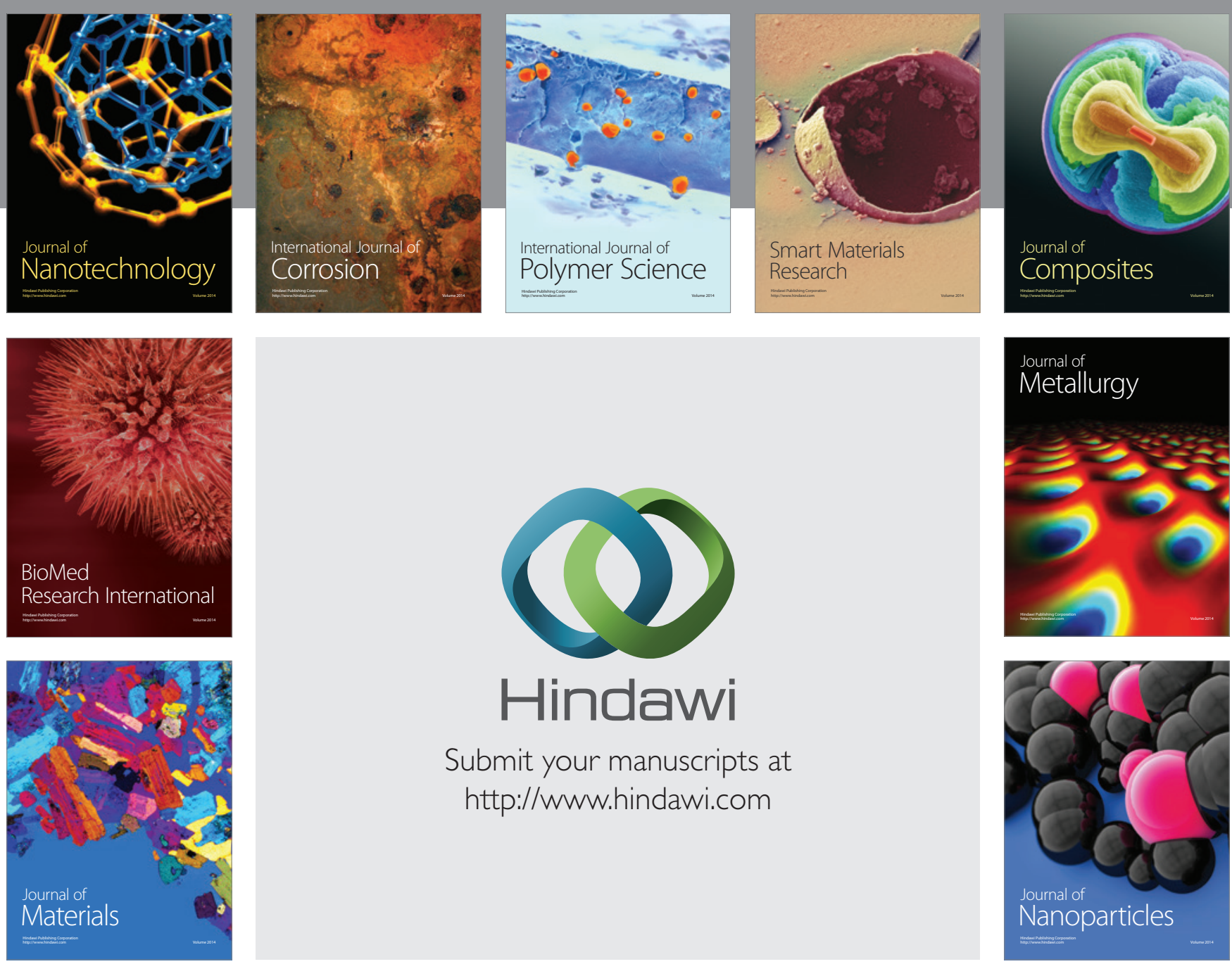

Submit your manuscripts at http://www.hindawi.com
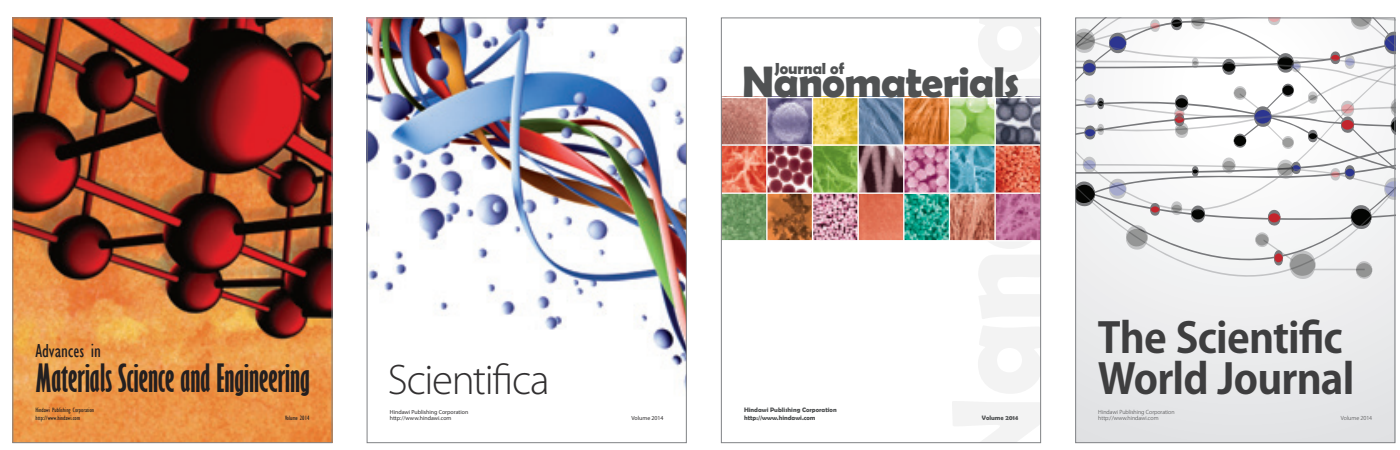

\section{The Scientific World Journal}
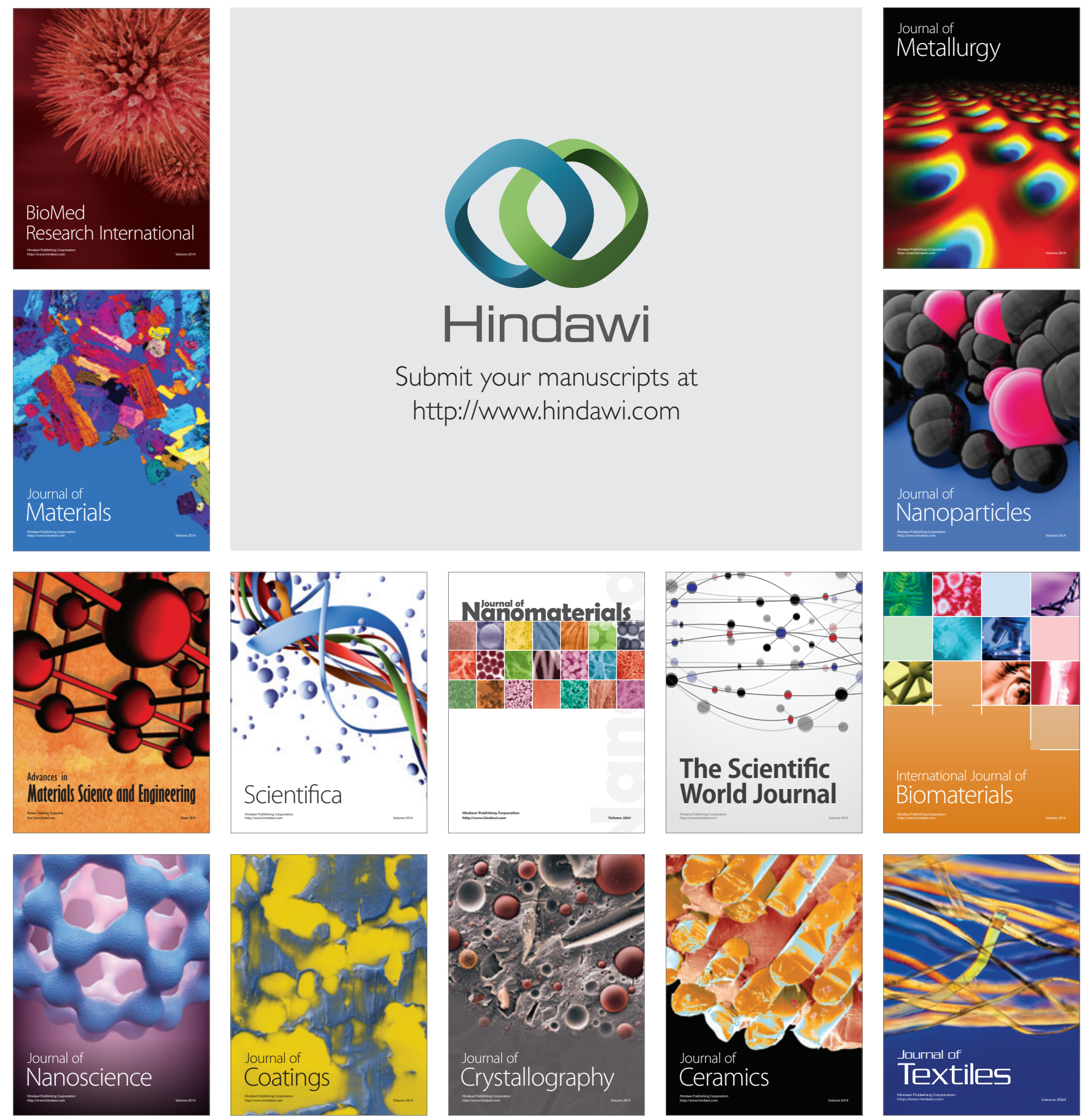